\title{
Dermoid cyst located in the floor of the mouth: case report
}

\author{
Juliana Portes de Oliveira, ${ }^{1,2}$ Danielle Castex Conde, ${ }^{1,2}$ Alexandre Moraes ${ }^{3}$ \\ ${ }^{1}$ Graduate Program in Pathology, Medical School, Fluminense Federal University, Niterói, RJ, Brazil \\ ${ }^{2}$ Department of Pathology, Medical School, Fluminense Federal University, Niterói, RJ, Brazil \\ ${ }^{3}$ Service of Oral and Maxillofacial Surgery, Hospital Municipal Salgado Filho, Rio de Janeiro, RJ, Brazil \\ - Conflicts of interest: none declared.
}

\section{Abstract}

Objective: to report a case of dermoid cyst addressing the criteria of clinical and histopathological diagnosis. Case report: seventeen-year-old patient with increased volume in the floor of the mouth. A biopsy was performed and the diagnosis was dermoid cyst. Intraoral enucleation of the lesion was performed, and no recurrence was observed after an 18-month follow-up. Conclusion: although some clinical features and imaging tests suggest this diagnosis, only histopathological examination can confirm it. Thus, it is important that the dental surgeon knows the lesion and possible morbidities that it can cause, enabling a precise diagnosis and appropriate management, thus benefiting the patient.

Keywords: Cyst; Dermoid cyst; Mouth.

\section{Introduction}

$\mathrm{D}$ ermoid cyst is a developmental cyst, ${ }^{1-4}$ covered by epithelium similar to the epidermis and containing cutaneous annexes on its wall. ${ }^{1-4}$ The most accepted etiology refers to the imprisonment of embryonic cells of 1 st and 2 nd branchial arches in the mesenchyme region, during the $3 \mathrm{rd}$ and 4 th week of embryonic life..$^{1-7}$

According to statistics, about $1.6 \%$ of dermoid cysts are found in the buccal cavity ${ }^{2,3}$, the floor of the mouth being the preferred location of this cyst, ${ }^{1-4}$ but it can also be found in other regions, such as on the side of the tongue, lips and jugal mucosa. ${ }^{1-3,7}$ The cyst does not have predilection for $\operatorname{sex}^{1,6,7}$ and it is more common in adults ${ }^{1-8}$ and children.,

Clinically, when it occurs in the floor of the mouth, the cyst presents a volume increase, slow growth, it is usually near the midline, well circumscribed, with the mucous membrane showing rosy yellowish color ${ }^{7}$ and asymptomatic. ${ }^{1-8}$ Depending on its size, the patient may exhibit symptoms, such as dysphagia, dysphonia and dyspnea because of the superior displacement of the tongue. ${ }^{1-3,6}$

During palpation, one can notice a lesion with a floating $^{2-4,7}$ or doughy ${ }^{1-3,8}$ consistency, for containing remains of keratin and sebaceous secretions in its interior.

Histopathologically, these cysts are covered by orthokeratinized stratified squamous epithelium, being possible to observe a prominent granular layer. In addition, its cystic wall consists of a fibrous connective tissue that contains one or more cutaneous annexes, such as sebaceous glands, hair follicles or sweat glands. The presence of abundant keratin inside the cystic lumen is a common finding. ${ }^{1-4}$

Most authors include the following injuries as differential diagnosis: ranula, Wharton's duct, thyroglossal tract cyst, cystic hygroma, branchial cleft cyst, acute infection in the floor of the mouth, infection of the adjacent salivary glands, and mass of normal fat in the submental space..$^{5-7}$

The treatment of choice is determined according to each case, considering the location and the size of the cyst, the most employed is the complete enucleation of the lesion through intraoral incision with referral of the piece to histopathological examination. ${ }^{1-9}$ The prognosis of this lesion is favorable ${ }^{5,9}$ and recurrence is rare. ${ }^{1,4,6-8}$

The objective of this study was to report a case of dermoid cyst located in the floor of the mouth, addressing diagnostic criteria and clinical manifestations, as well as the treatment and clinical follow-up of 18 months.

\section{Case Report}

Brown-skinned patient, female, 18 years old, admitted to the emergency Service of Oral and Maxillofacial Surgery at Hospital Municipal Salgado Filho (HMSF), complaining of "difficulty breathing and swallowing," without painful symptoms.

Anamnesis was held, in which the patient reported not having systemic diseases and also denied any chemical allergies. She also reported that never underwent a surgery in the past and that was unaware of the family medical history.

In the oral physical examination (Figure 1), we noticed a small increase in submental volume, which showed the presence of "double chin" (Figure 2), as well as volume increase in the midline of the floor of the mouth, with normal coloring and texture, causing the superior displacement of the tongue, which justified the main complaint of the patient. During palpation, the lesion presented doughy consistency and when subjected to digital pressure, the fingermarks remained for a few seconds. The patient could not inform the exact time of the lesion evolution, but reported that it was growing slowly. 


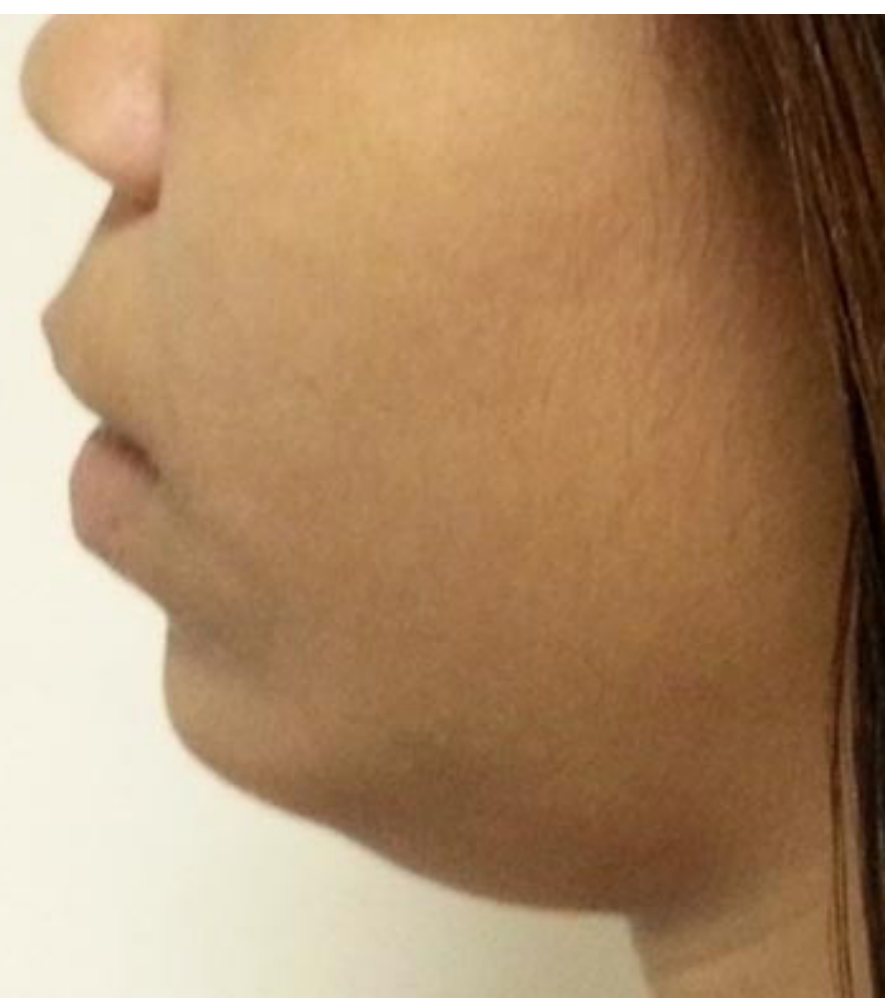

Figure 1. Image showing the clinical aspect of double chin

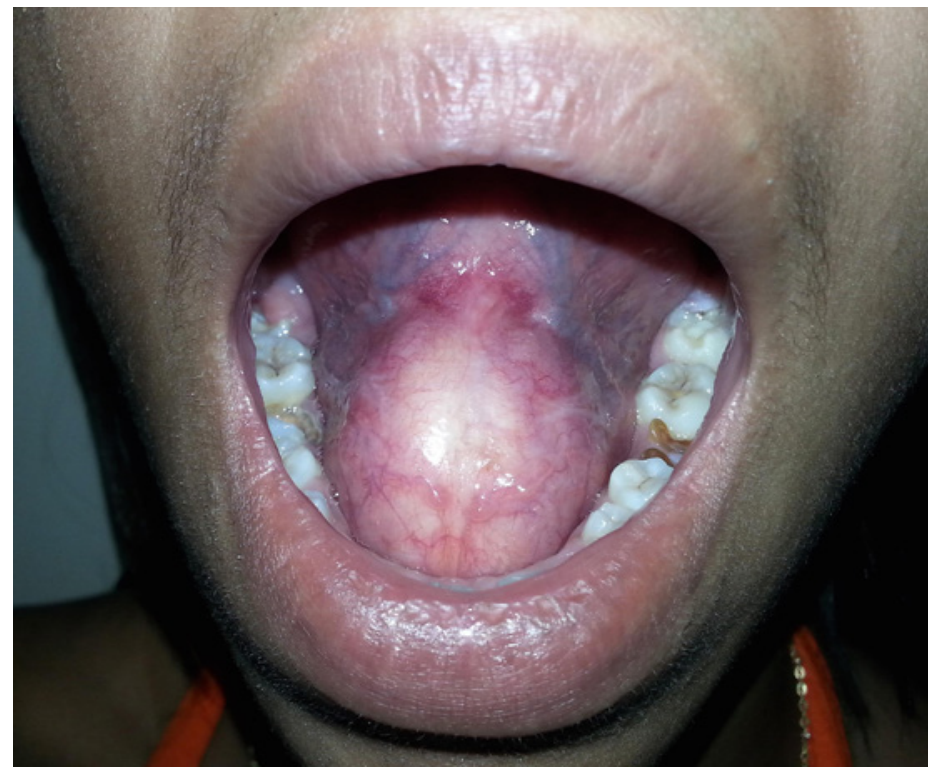

Figure 2. Image showing the volume increase in the floor of the mouth

Ultrasound examinations (US) of the floor of the mouth and facial computed tomography (CT) were requested. The report on the ultrasound described "a cystic image with high protein content located on the midline between the extrinsic muscles of the tongue base. The relationship between the lesion and the submandibular gland was not observed. The lesion measures 6.1 x 3.4 x 3.7 cm."

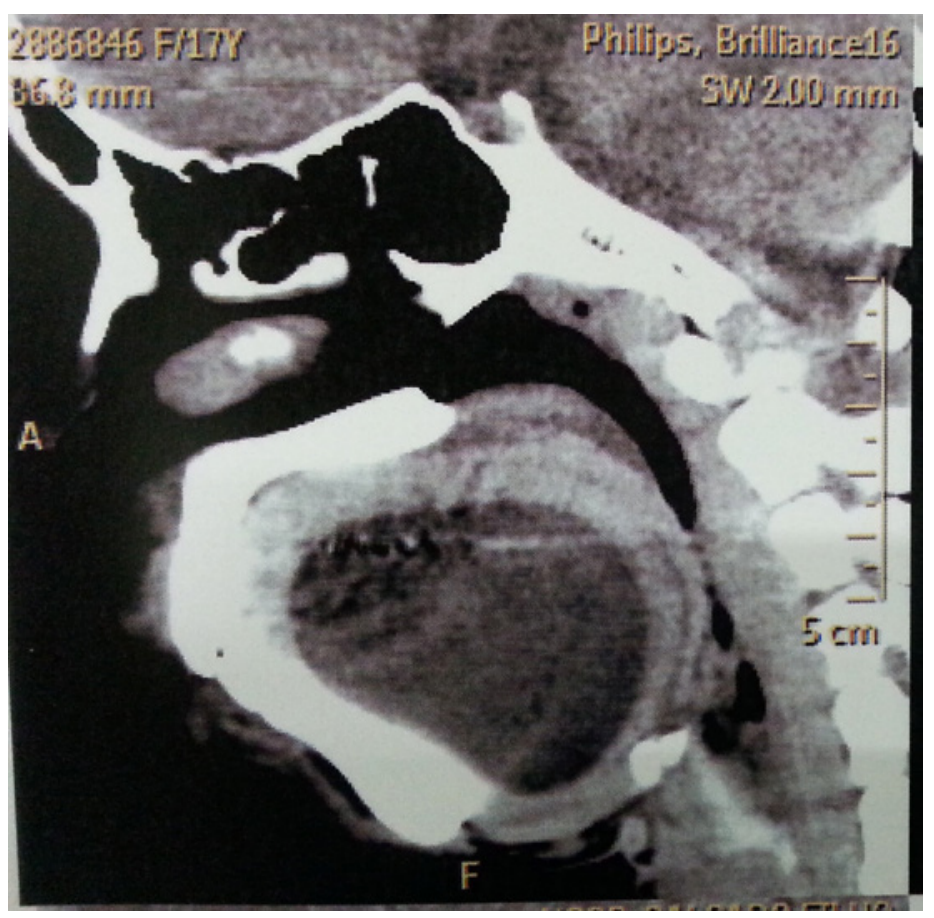

Figure 3. Computed Tomography scan in sagittal section

When assessing the tomographic image (Figure 3), a cystic lesion was detected again in the sublingual region, measuring $5.5 \times 4.5 \times 3.0 \mathrm{~cm}$.

Based on the clinical and tomographic characteristics and on the aspects observed in the ultrasound, two hypotheses were formulated: dermoid cyst and epidermoid cyst.

The surgery was performed in the hospital's surgical center under general anesthesia with nasopharyngeal intubation, where an intraoral vertical incision was conducted in the midline of the ventral surface of the tongue and floor of the mouth to access the anatomical region where the cyst was, above the geniohyoid muscle. Blunt dissection was performed, separating the fibrous cystic capsule from the surrounding tissues, allowing the removal of the lesion (Figures 4 and 5). We observed doughy mass of whitish coloration in the interior of the lesion. The surgery showed no complications and the material was referred to histopathological examination in the Pathology Service of the HMSF. The day after surgery, the patient was discharged with the necessary guidelines, presenting a good postoperative recovery. 


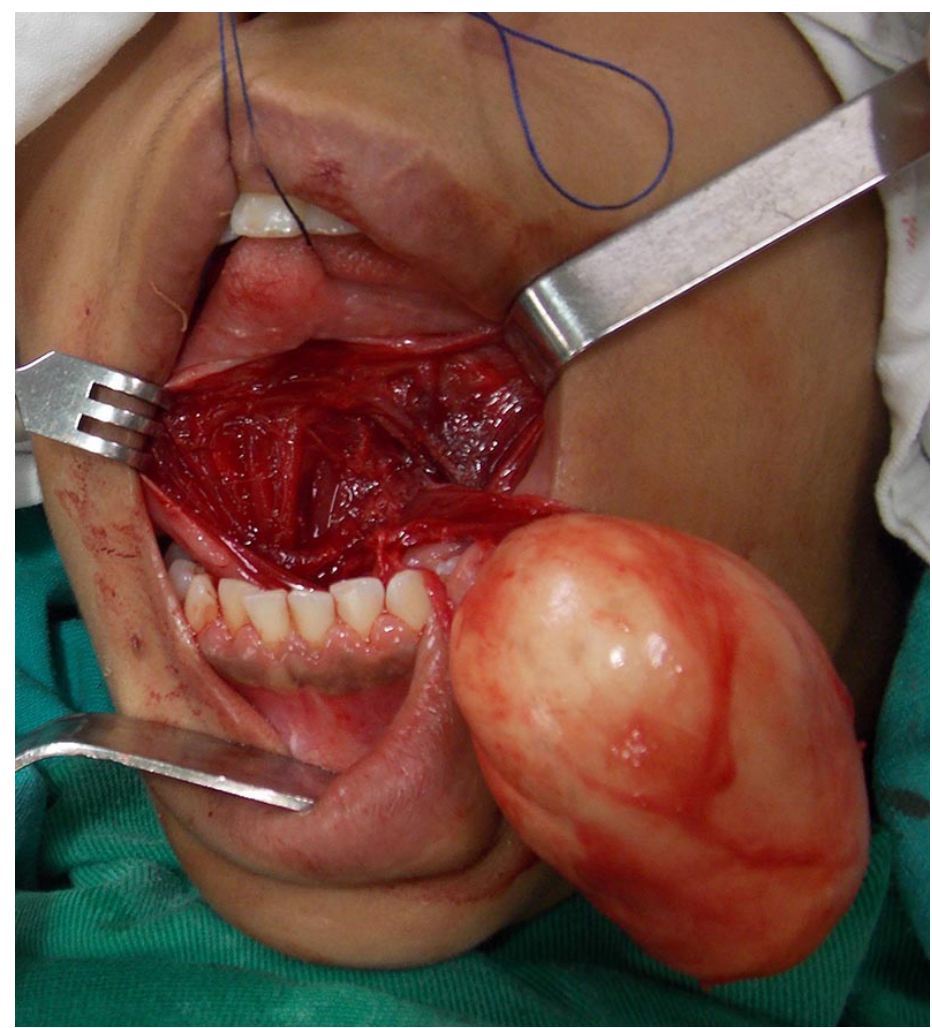

Figure 4. Enucleation of the lesion

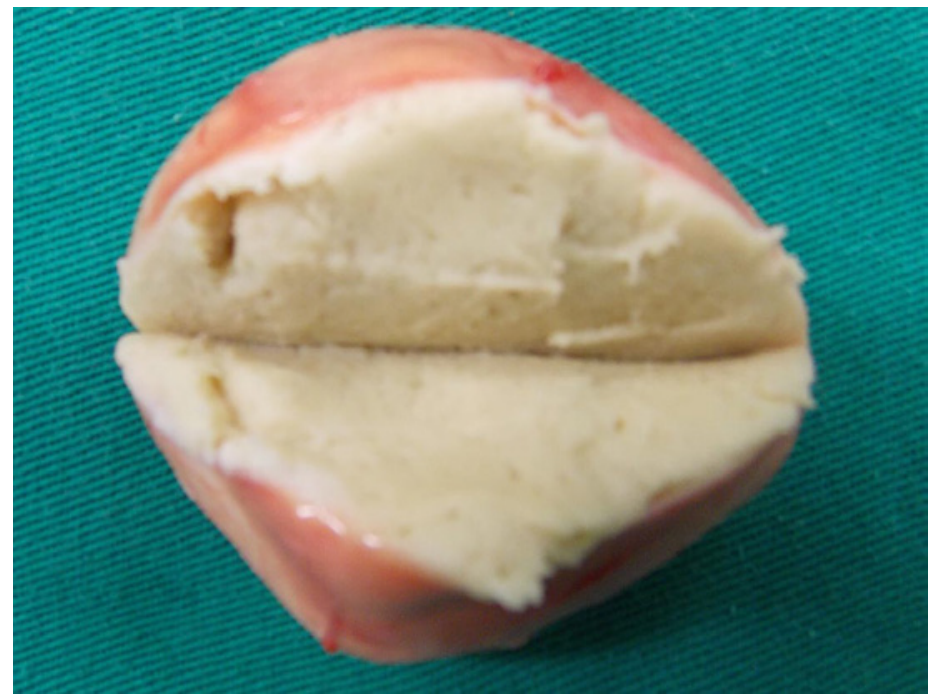

Figure 5. Macroscopic aspect of the lesion after longitudinal section. To observe the keratinized material in its interior

Gross examination of the lesion Showed "a nodular formation apparently encapsulated, measuring $4.0 \times 3.5 \times 3.0$ $\mathrm{cm}$, submitted partially open, represented by cyst-like lesion with doughy yellowish content." The histopathological cuts stained with hematoxylin and eosin (HE) showed a cystic lesion covered with orthokeratinized stratified squamous epithelium with a prominent granular layer, containing keratin on its cavity. The presence of sebaceous cells was observed on the cystic wall (Figure 6). With these microscopic char- acteristics the diagnosis of dermoid cyst was completed.

After 18 months, the patient returned to the outpatient

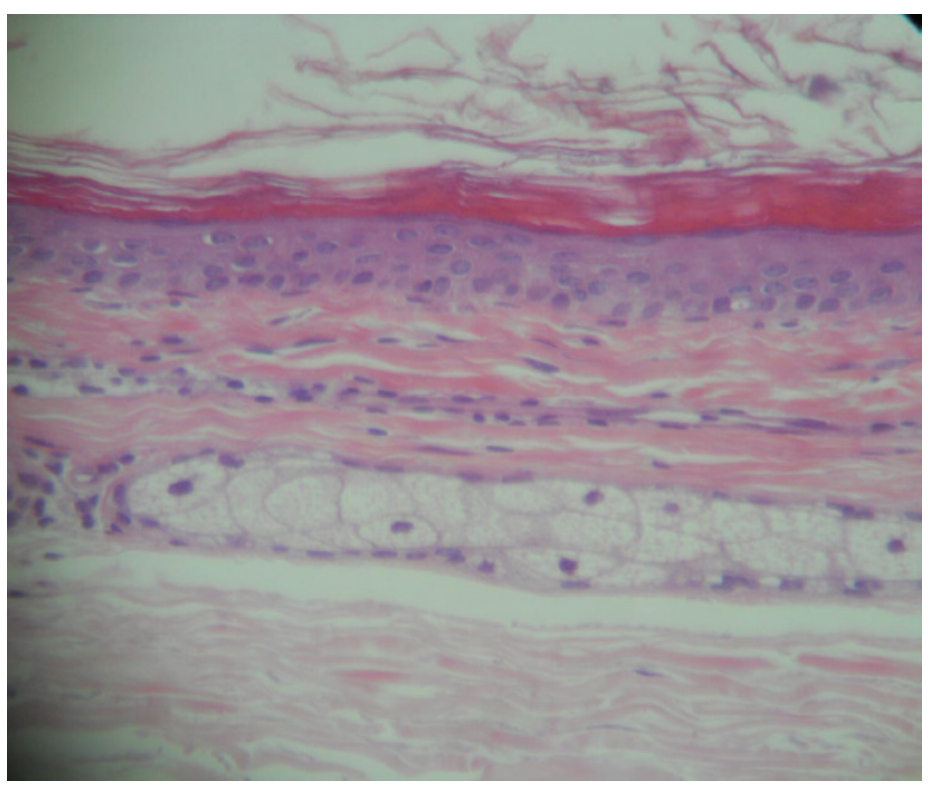

Figure 6. Histopathological exam showing the cyst covered by an orthokeratinized stratified squamous epithelium and cutaneous annexes (sebaceous glands) in the fibrous capsule (HE 40x)

clinic of Oral and Maxillofacial Surgery of the HMSF for the follow-up, and no sign of cyst recurrence was detected.

\section{Discussion}

In a study at the Mayo Clinic, in 1937, a total of 1,495 dermoid cysts, 103 (6.9\%), occurred in the head and neck region, of these, $24(1.6 \%)$ cysts occurred in the floor of the mouth. ${ }^{8}$

The dermoid cyst can be classified into two large categories: congenital and acquired. ${ }^{3,5,6}$ The congenital theory suggests that the cyst comes from pluripotent tissues that are trapped in the midline during the merger of the first and second branchial arches in the 3rd and 4th week of intrauterine life. ${ }^{4,6,7}$ The acquired theory suggests the formation of the cyst through the implantation of epithelial cells in deep tissue after a trauma. Makos et al., ${ }^{6}$ even suggest a third theory for the origin of this cyst, which is a variation of the thyroglossal duct cyst.

In histopathological terms, the dermoid cysts were classified by Meyer in $1955^{9}$ into 3 types: epidermoid cyst, showing the wall limited by stratified squamous without cutaneous annexes; dermoid cyst, limited by stratified squamous epithelium with one or more cutaneous annexes, such as sebaceous and sweat glands and hair follicles; and teratoma, which represents a cavity surrounded by epithelium with mesoderm, ectoderm and endoderm derivatives, showing, besides the typical cutaneous annexes of the dermoid cyst, vascular formations, muscle, bone, cartilage, dental tissues and even entire teeth. ${ }^{3,4,6,8,9}$ 
No clinical characteristics can differentiate these three types of cysts, however, the epidermoid cyst is less common than the dermoid cyst in the head and neck region. ${ }^{6}$

According to this classification, the cyst reported in this study is qualified as a dermoid cyst, for showing cutaneous annexes (sebaceous glands) in its fibrous capsule.

Another classification has the anatomy as reference, in which Katz \& Passy ${ }^{4}$ classified dermoid and epidermoid cysts of the floor of the mouth as: sublingual located in the midline under the tongue, between the geniohyoid and mylohyoid muscles, and when it reaches large proportions, the tongue is shifted to the oropharynx; geniohyoid, in the midline of the submental region between the skin and the geniohyoid muscles, leading to a clinical appearance of double chin; lateral cyst in the submandibular region, usually showing a growth toward the hyoid bone or superiorly compressing the floor of the mouth, forcing the tongue to the opposite side. ${ }^{4}$ Makos et $a l .{ }^{6}$ call these types of cysts previously classified as genioglossus median, geniohyoid median, and lateral, respectively. ${ }^{6}$

Therefore, the anatomical location of this cyst will interfere in the clinical aspect. ${ }^{6,8}$ The symptoms of dysphagia, dyspnea and dysphonia occur by displacement of the tongue because of this sublingual increase. ${ }^{3}$

In the case exposed, the patient presents two clinical characteristics mentioned above, which are the superior displacement of the tongue and double chin, indicating that the dermoid cyst could be classified as either Sublingual or Geniohyoid, according to the classification by Katz \& Passy. ${ }^{4}$

Teszler et al. apud Sahoo et al. ${ }^{10}$ classified dermoid cysts into three anatomical-surgical types: supramylohyoid (intraoral or sublingual), inframylohyoid (cervical) and periand transmylohyoid (intraoral and cervical). ${ }^{10}$

The lesion is most common between 15 and 35 years old $^{2,3}$ as presented in the case reported, in which the patient was 18 years old. However, these cysts may develop in children and can even be present at the moment of birth. ${ }^{4}$

In cases where the volume increase is sudden, some causes can be associated, such as the onset of puberty, when there is an increase in the secretion of sebum by the sebaceous glands ${ }^{8}$, and secondary infection caused by salivary ducts blocked by the cyst or by oral microorganisms formed by trauma in the region, thus causing pain, fever, trismus, dysphagia, odynophagia, and cervical lymphadenopathy. ${ }^{6,8}$ In the case presented it was not possible to know the time of evolution, because the patient had not noticed the lesion, just reported breathing difficulty. In addition, we did not observe any symptoms that would indicate an infectious process in the location.

Imaging tests such as the computed tomography and magnetic resonance may show the exact location and size of the lesion and its relationship with adjacent structures, being of great value to the decision of surgical strategy., ${ }^{3,4,6,8}$ The ultrasound examination besides helping to identify the location and size of the structure, ${ }^{3,4,6,8}$ also can be useful in differentiating between a vascular or cystic lesion, ${ }^{3,4,6,8}$ and fine needle aspiration can be the first step for the differential diagnosis, in which a creamy and whitish content with keratin debris can be observed. ${ }^{3,8}$ However, for Santos et al.,$^{5}$ aspiration biopsy is not indicated because of the possibility for a secondary infection to develop. These authors report a case of dermoid cyst infected after the aspiration procedure that clinically mimicked a Ludwig's angina. ${ }^{5}$

Despite the assistance of these procedures in the differential diagnosis and in the assessment of extension, location and relation between the lesion and the adjacent structures, only the histopathological examination can confirm the diagnosis. ${ }^{3,6}$

The enucleation of the lesion can be made by intraoral access, when the lesion is located above the geniohyoid muscle, or extraoral when the lesion is located below this muscle, ${ }^{1,3,6}$ in a large lesion or one associated with infectious processes that may interfere with the patient's airway. ${ }^{5,6}$ Also, a combination of the two techniques can be chosen. ${ }^{5,6}$ In this case, we chose an approach only through intraoral access because of the superficial location of the cyst in this region, avoiding to compromise the patient's aesthetics.

During excision, lacrimal probes or gutta-percha cones can be used to protect the ducts of the salivary glands, preventing these structures from injury during the surgical procedure. ${ }^{8}$ One must also be careful not to rupture the cyst during surgery, because the cystic content can irritate the fibrovascular tissue, causing postoperative inflammation. ${ }^{3}$

The prognosis of this lesion is great, ${ }^{4,6}$ however Utumi et al. ${ }^{4}$ suggest a postoperative follow-up of at least three years in all cases. Despite the rarity, the possibility of malignant transformation to squamous-cell carcinoma must be considered. ${ }^{1,4,8}$ Some authors relate a greater chance of malignancy for teratomas. ${ }^{6}$

The chance of recurrence is very low ${ }^{1,4,6-9}$, mainly because of the thick fibrous capsule of this cyst, which facilitates the removal. ${ }^{8}$

\section{Conclusion}

The dermoid cyst is a rare developmental cyst in the head and neck region. Although some clinical characteristics and images obtained in the computed tomography and ultrasonography exams suggest its diagnosis, only the histopathological examination can confirm it. Thus, it is 
important that the dental surgeon knows this lesion and possible morbidities that it could cause, enabling a precise diagnosis and appropriate management, thus benefiting the patient. Tumor enucleation is the treatment of choice and the prognosis is usually good, with low rates of recurrence. In this case, after an 18-month follow-up, no signs of recurrence were observed.

\section{References}

1. Neville BW, Damm DD, Allen CM, Bouquot JE. Patologia Oral e Maxilofacial. 3. ed. Rio de Janeiro: Elsevier, 2009.

2. Shear M, Speight PM. Cistos da Região Bucomaxilofacial. 4. ed. Livraria Santos, 2011.

3. Sahoo NK, Choudhary AK. Dermoid cyst of floor of mouth: a case report. Nat Jour of Med and Dent Res. 2012;1(1):24-30.

4. Utumi ER, Zambon CE, Pedron IG, Machado GG, Rocha AC. Recidiva de cisto dermoide congênito de localização paramediana. Arq Int Otorrinolaringol. 2010;14(3):368-72.

5. Santos TS, Gomes ACA, Frota R, Oliveira e Silva ED, Martins Filho PRS, Andrade ESS. Iatrogenic infection in dermoid cyst of the floor of the mouth. Braz J Otorhinolaryngol. 2011;77(5):675.

6. Makos C, Noussios G, Peios M, Gougousis S, Chouridis P. Dermoid cysts of the floor of the mouth: Two Case Reports. Cas Rep in Med. 2011;2011(362170):1-6.

7. Carvalho FCR, Taira NV, Carvalheira TB, Silva DM, Gonçalves PAM. Cisto dermoide no assoalho bucal: relato de caso. Rev Clin Pesq Odontol. 2009;5(2):161-4. 8. Seah TE, Sufyan W, Singh B. Case report of a dermoid cyst at the floor of the mouth. Ann Acad Med. 2004;33:77-9.

9. Meyer I. Dermoid cyst of the floor of the mouth. Oral Surg, Oral Medic, Oral Path. 1955; 8:1149-1164. Apud Shear M \& Speight PM. Cistos da Região Bucomaxilofacial. Tradução Paulo Henrique Orlato Rossetti et al. 4. ed. Livraria Santos, 2011, 228

10. Teszler CB1, El-Naaj IA, Emodi O, Luntz M, Peled M. Dermoid Cysts of the lateral floor of the mouth: A comprehensive anatomo-surgical classification of cysts of the oral floor. J Oral Maxillofac Surg. 2007;65(2):327-32. Apud Sahoo NK, Choudhary AK. Dermoid cyst of floor of mouth: a case report. National Journal of Medical and Dental Research. 2012;1(1): 24-30.

\section{Mini Curriculum and Author's Contribution}

1. Juliana Portes de Oliveira - DDS. Contribution: performed the surgery, effective scientific and intellectual participation in the study; study conception and design; data collection; data interpretation; manuscript preparation; manuscript writing; critical review and final approval.

2. Danielle Castex Conde - DDS and PhD. Contribution: performed effective scientific and intellectual participation in the study; study conception and design; data collection; data interpretation; manuscript preparation; manuscript writing; critical review and final approval.

3. Alexandre Moraes - DDS and MSc. Contribution: performed the surgery, effective scientific and intellectual participation in the study; study conception and design; data collection; data interpretation; manuscript preparation; manuscript writing; critical review and final approval.

Submitted: 09/30/2017 / Accepted for publication: 12/03/2017

Corresponding Author

Danielle Castex Conde

E-mail: daniellecastex@yahoo.com.br 